\title{
KNOWLEDGE MANAGEMENT CYCLE: A SCIENTIFIC LITERATURE REVIEW
}

\author{
Mirna Kordab ${ }^{1}$, Jurgita Raudeliūniene ${ }^{2}$ \\ 1,2Department of Business Technology and Entrepreneurship, \\ Vilnius Gediminas Technical University, Saulètekio al. 11, Vilnius, Lithuania

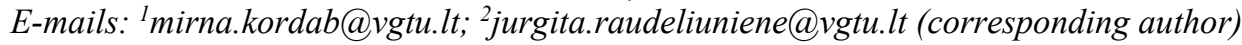

\begin{abstract}
Recently the knowledge management processes are analysed as the main source of uniqueness for the organisations, while they are facing the challenge of implementing the most efficient processes that affect their performance (Chang, Hsu, \& Yen, 2012; Kianto, Vanhala, \& Heilmann, 2016; Raudeliūnienè \& Meidutè-Kavaliauskienė, 2016; Raudeliūnienè, Davidavičienė, \& Jakubavičius, 2018; Känsäkoski, 2017). The scientists distinguish different combinations of knowledge management processes in approaching the knowledge management process and analysis has shown that knowledge management processes, studied by most scientists, do not have a clear knowledge management structure (García-Fernández, 2015; Raudeliūnienė et al., 2018). The purpose of this study is to examine the knowledge management concept and knowledge management cycle considering the different interpretations of scientists. The study is grounded on scientific literature review.
\end{abstract}

Keywords: knowledge, knowledge management, knowledge management cycle, knowledge management processes, evaluation.

JEL Classification: M1, M16, D8, D83.

\section{Introduction}

In recent years, globalization and technology development, affecting not only society information needs, but also organisations structural issues, have dominated and created many challenges for organisations that strive to create and develop uniqueness in a complex and dynamic environment. Organisations face challenges in responding to fast changes of dynamic market trends, and they are threatened by the risk of failing to adapt with the new technological, economic, social, cultural, political, legal and other issues. Thus, the increasingly significant role of knowledge, as a unique source, has motivated organisations to consider knowledge management as an efficient approach in different management practices and a means to control the access to opportunities and advancement in the twenty-first century (Pawlowski \& Bick, 2012; Raudeliūnienė \& MeidutèKavaliauskienè, 2016; Raudeliūnienė et al., 2018; Akbari \& Ghaffari, 2017).

Knowledge management started to be known as a discipline in the beginning of 1990s (Pauleen \& Wang, 2017) and over the years it became of interest to many scientists and practitioners who studied different areas related to knowledge management processes and their effect on the organisational performance (Massingham \& Al Holaibi, 2017). Most researchers have recognized knowledge management as a crucial factor for organisations' success since it positively affects employees and customers satisfaction, and it is the main resource for increasing efficiency of the organisations' performance, which leads to building organisational uniqueness in the current dynamic environment (Cepeda-Carrion, Martelo-landroguez, LealRodríguez, \& Leal-Millán, 2017; Mageswari, Sivasubramanian, \& Dath, 2017; Matoskova \& Smesna, 2017; Alavijeh, Esmaeili, Sepahvand, \& Davidavičienè, 2018).

Knowledge's recognition as a strategic resource changed the rules of competition, management practice and strategy formation process and urged organisations to develop and strengthen their knowledge management cycle (Shahzad, Bajwa, Siddiqi, Ahmid, \& Raza Sultani, 2016) in order to achieve uniqueness in the challenging and unpredictable market (Valmohammadi \& Ghassemi, 2016). Accordingly, it becomes necessary for organisations to invest time and financial recources for acquir- 
ing knowledge, organising it and using it efficiently (Akbari \& Ghaffari, 2017) in order to be global or local leaders (Valmohammadi \& Ghassemi, 2016). Worldwide, more than $\$ 600$ million are invested annually by the World Bank in knowledge services and around \$4 billion per year are spent through loans, budget, and partnership activities in knowledge management services. Given all these investments in knowledge management systems, studies show that organisations are facing a loss of around $\$ 31.5$ billion each year by failing to achieve their knowledge management goals efficiently (Hesamamiri, Mahdavi Mazdeh, Jafari, \& Shahanaghi, 2015).

Summarizing various scientific opinions, knowledge management is defined, as targeted and systematic management of processes, methods and tools, making full use of the organisation's knowledge potential for strategic goals, making effective decisions and implementing and creating its value (Raudeliūnienè \& Meidutè-Kavaliauskienè, 2016; Raudeliūnienè et al., 2018). Organisations have shifted from managing the existing information to creating new knowledge that improves organisational productivity and performance and they started introducing knowledge management processes to ensure that knowledge is accessible for all the members in the organisation and is available at the right time to the right person (Chang et al., 2012; Sangari, Hosnavi, \& Zahedi, 2015; Känsäkoski, 2017). Knowledge management processes include the creation, acquisition, storage, transfer, sharing and application of knowledge, which implementation should be embedded in the whole organisational strategy (Hesamamiri, Mahdavi Mazdeh, \& Bourouni, 2016) because the fit between knowledge management system capabilities and processes determine knowledge management performance. However, studies report that the majority of knowledge management systems have failed, resulting in huge losses because organisations were unable to identify their knowledge requirements properly and to implement the appropriate strategies that meet those requirements (Chang et al., 2012). The main requirement for efficient knowledge management is the coordination and implementation of knowledge management processes as part of the daily activities because they facilitate transforming personal knowledge into corporate knowledge that can be of benefit to the organi- sations (Sangari et al., 2015), while the challenge for the organisations remain choosing the key knowledge processes that best support the organisational strategies such as innovation, continuous learning and collaborative decisionmaking (Ranjbarfard, Aghdasi, López-Sáez, \& Emilio Navas López, 2014). The way to develop and implement the best knowledge management processes that lead organisations to achieve their desired outcomes is still vague and needs more interpretations (Shahzad et al., 2016).

The purpose of this study is to examine the knowledge management concept and knowledge management cycle considering the different interpretations of scientists. In this research, the analysis of knowledge management processes will be grounded on previous scientific literature review in order to determine what the main processes that affect the organisation's performance are.

\section{Theoretical evaluation aspects of knowledge management}

\subsection{Knowledge definition}

Knowledge is considered amongst the most essential and crucial assets in the current unstable environment. Successful organisations are those that constantly create new knowledge with minimum human, financial, technology and other resources, spread and use it through the organisation for creating value (Schiuma, Carlucci, \& Lerro, 2012; Wee \& Chua, 2013; Acar, Tarim, M. Zaim, H. Zaim, \& Delen, 2017). The improvement of innovation and technologies which are the knowledge sub-systems is the most actual problem for humanity and the judgment on them may reveal which methods for improvement are feasible and which strategies and procedures are sustainable and successful (Ashok, Narula, \& Martinez-Noya, 2016). Rather than competing based on physical and monetary capital, the achievement of organisations is affected by the knowledge and the skills of its workers and members (Wee \& Chua, 2013).

Knowledge has been interpreted from different points of view (Anand, Kant, Patel, \& Singh, 2015; Gupta \& Bhattacharya, 2016; Kianto et al., 2016; Akbari \& Ghaffari, 2017; Massingham \& Al Holaibi, 2017). Knowledge is defined as the capability of a person to assess information and use it in a productive way. Individuals utilize the knowledge that they gained through experiences, which are the result of their interaction. Knowledge 
is considered as a combination of know-how, techniques, judgments, perspectives and values that people hold during their life (Shahzad et al., 2016). Accordingly, organisations have perceived knowledge as the power and the main origin of uniqueness because it is difficult to imitate.

Scientists differentiate between the three terms: data, information and knowledge. Data is discrete raw facts which will be interpreted; information is organized and meaningful data, whereas knowledge represents the systems and procedures that lead the decision making process (Anand et al., 2015). Knowledge might be comprehensively characterized as reliable information that is of real benefit to an organisation. Knowledge refers to the capacity of doing efficient tasks and successful activities (Massingham \& Al Holaibi, 2017).

The capacity of individuals to use and create new knowledge depends on their personal, professional, social, management and other competencies. It is the human capacity to interpret the information acquired and convert this information to knowledge which gives the individuals the chance to build up their own particular instinct and advancement (Little \& Deokar, 2016). Since knowledge is a significant resource for organisations, it should be managed in order to assist them to survive in various situations and maintain efficiency as well as uniqueness. Different methods are required to collect and process knowledge in order to benefit from it in the organisations (Oluikpe, 2015; Omotayo, 2015; D. Mishra, Aydin, A. Mishra, \& Ostrovska, 2018).

\subsection{Knowledge management concept}

Knowledge management has been perceived as a main tool for improving an organisation's ability to accomplish success (M. Chugh, N. Chugh, \& Punia, 2015). Based on the awareness of the significance of intangible and intellectual resources, most organisations have started to implement a variety of procedures to create, store and share knowledge internally. Accordingly, the knowledge management procedure can be characterized as a systematic process for obtaining, organizing, and transferring the knowledge of employees to be useful for other employees in the same organisation. Managers should find where knowledge resources are available within the organisation and how the employees can contribute to the knowledge management strategy where employees are considered as knowledge transmitters. Knowledge management systems intend to utilize the skills and experiences of the employees and to add value by joining individuals in teams to benefit from the available information and use it to satisfy the organisation's needs and serve as competitive advantage (Chang \& Lin, 2015; Hegazy \& Ghorab, 2015; Nowacki \& Bachnik, 2016; Hwang, 2016; Bican, Guderian, \& Ringbeck, 2017; Hashemi, Khadivar, \& Shamizanjani, 2018). Knowledge management involves recognizing and utilizing the knowledge available in an organisation in order to increase its uniqueness. It consists of knowledge processes like creation and sharing, as well as infrastructures, capacities and activities that maintain those processes (Tubigi \& Alshawi, 2015; Kianto et al., 2016; Muthuveloo, Shanmugam, \& Teoh, 2017). Knowledge management also involves the strategies and processes that transform intellectual resources and information in order to add value to the organisation. Knowledge management is turned into a critical factor for organisations' success and advancement, making it hard for the organisations that did not implement knowledge management systems to maintain competitive advantages or a good market position (Shahzad et al., 2016). Knowledge management is the system through which the creation, storage, and sharing of significant information and experiences are maintained in the societies and organisations that have the same needs. It is considered as a competitive instrument which is able to benefit from the available assets with the implementation of the best practices that lead to the improvement of organized capacities in the organisational and individual plans, supporting the creation of new knowledge or discovering the intellectual capital and knowledge available in the organisation (Wahba, 2015). Knowledge management is also a combination of ideas obtained from knowledge systems, business process reengineering, software engineering, human resource management, and organisational behavior. The main role of knowledge management is to transform tacit to explicit knowledge by using technologies and personal factors such as leadership, culture, strategy and motivation (Anand et al., 2015). Knowledge management covers many activities such as database management systems, organisational culture, social education and other aspects (McIver \& Lepisto, 2017). Many organisations im-plement knowledge management strategies after recognizing the importance of knowledge as an intangible resource. Organisational structure and culture is essential in supporting the knowledge management strategy. An appropriate strategy facilitates identifying future 
trends, foreseeing conceivable situations, decreasing expected risk, increasing expertise, and reorganizing the routine activities (Nowacki \& Bachnik, 2016). By implementing knowledge management, organisations that operate in an environment which is unpredictable and hard to control, can enhance their capacities of creating, managing, and sharing their knowledge, increase their intelligence, improve the efficiency of their decision making process in order to accomplish a greater performance (Hegazy \& Ghorab, 2015). Knowledge management enhances also the decision making process (Yap \& Lock, 2017).
Knowledge management is a valuable instrument that can contribute to the change of the organisational culture and lead to a better performance in a friendly environment (Pfister \& Eppler, 2012; Luhn, Aslanyan, Leopoldseder, \& Priess, 2017). Knowledge management implementation can foster the response to key issues, enhance the employees abilities, improve productivity, increase revenues, reduce costs, generate more forecasts and better attract and retain personnel (Edvardsson \& Durst, 2013; Luhn et al., 2017; Yap \& Lock, 2017).

Table 1. The spectrum of knowledge management processes (source: created by the authors)

\begin{tabular}{|c|c|c|c|c|c|c|c|}
\hline \multirow[b]{2}{*}{ Authors, years } & \multicolumn{7}{|c|}{ Knowledge management processes } \\
\hline & $\begin{array}{l}\text { Creation / } \\
\text { genera- } \\
\text { tion }\end{array}$ & $\begin{array}{l}\text { Sharing / } \\
\text { transfer / dis- } \\
\text { tribution / dis- } \\
\text { semination / } \\
\text { conversion }\end{array}$ & $\begin{array}{l}\text { Applica- } \\
\text { tion/re- } \\
\text { use / in- } \\
\text { terpreta- } \\
\text { tion }\end{array}$ & $\begin{array}{l}\text { Acqui- } \\
\text { sition / } \\
\text { capture }\end{array}$ & $\begin{array}{l}\text { Storage / } \\
\text { codifica- } \\
\text { tion / re- } \\
\text { tention }\end{array}$ & $\begin{array}{l}\text { Organi- } \\
\text { zation }\end{array}$ & $\begin{array}{l}\text { Protec- } \\
\text { tion }\end{array}$ \\
\hline $\begin{array}{l}\text { Liu, Chai, and } \\
\text { Nebus, } 2013\end{array}$ & & & $X$ & & & & \\
\hline $\begin{array}{l}\text { Wee and Chua, } \\
2013\end{array}$ & $\mathrm{X}$ & $\mathrm{X}$ & $\mathrm{X}$ & & & & \\
\hline $\begin{array}{l}\text { Obeidat, Masa'deh, } \\
\text { and Abdallah, } 2014\end{array}$ & & $\mathrm{X}$ & $\mathrm{X}$ & $\mathrm{X}$ & $X$ & & \\
\hline $\begin{array}{l}\text { Ranjbarfard et al., } \\
2014\end{array}$ & $\mathrm{X}$ & $X$ & $X$ & & $X$ & & \\
\hline Al Saifi, 2015 & $\mathrm{X}$ & $\mathrm{X}$ & $\mathrm{X}$ & & & & \\
\hline $\begin{array}{l}\text { Chang and Lin, } \\
2015\end{array}$ & $X$ & $X$ & $X$ & & $\mathrm{X}$ & & \\
\hline Sangari et al., 2015 & $\mathrm{X}$ & $\mathrm{X}$ & $\mathrm{X}$ & $\mathrm{X}$ & $\mathrm{X}$ & $\mathrm{X}$ & \\
\hline $\begin{array}{l}\text { Schenk, Parent, } \\
\text { MacDonald, and } \\
\text { Proulx Therrien, } \\
2015\end{array}$ & $\mathrm{X}$ & & & & & & \\
\hline Suorsa, 2015 & $\mathrm{X}$ & & & & & & \\
\hline Tongo, 2015 & $\mathrm{X}$ & $\mathrm{X}$ & $\mathrm{X}$ & & $X$ & & \\
\hline Wahba, 2015 & $\mathrm{X}$ & $\mathrm{X}$ & $\mathrm{X}$ & & & & \\
\hline Kianto et al., 2016 & $\mathrm{X}$ & & & $\mathrm{X}$ & $\mathrm{X}$ & & \\
\hline $\begin{array}{l}\text { Lee, Shiue, and } \\
\text { Chen, } 2016\end{array}$ & $\mathrm{X}$ & $\mathrm{X}$ & & & & & \\
\hline $\begin{array}{l}\text { Little \& Deokar, } \\
2016\end{array}$ & $\mathrm{X}$ & & & & & & \\
\hline Känsäkoski, 2017 & $\mathrm{X}$ & $\mathrm{X}$ & $\mathrm{X}$ & & & & \\
\hline $\begin{array}{l}\text { Matoskova \& } \\
\text { Smesna, } 2017\end{array}$ & & $\mathrm{X}$ & & & & & \\
\hline $\begin{array}{l}\text { Pandey, Dutta, and } \\
\text { Nayak, } 2018\end{array}$ & & $X$ & $X$ & $X$ & & & $X$ \\
\hline $\begin{array}{l}\text { Raudeliūnienè } \\
\text { et al., } 2018\end{array}$ & $X$ & $X$ & $X$ & $X$ & $X$ & & \\
\hline
\end{tabular}




\section{Knowledge management processes}

Knowledge management consists of knowledge processes that maintain organisational processes such as innovation, individual learning, collective learning and collaborative decision-making (Ranjbarfard et al., 2014). Knowledge management processes are crucial for an efficient knowledge management. They involve transforming individual knowledge into corporate knowledge that can be broadly exchanged and properly implemented. By applying knowledge management processes to the daily activities, organisations can maintain competitive advantage and compete in the current markets (Sangari et al., 2015).

Knowledge management processes can be defined as all of the activities that are related to knowledge and carried in the organisations by internal or external parties. Knowledge management processes differ from one organisation to another and the number of these processes is not agreed upon among scientists (Liu et al., 2013; Wee \& Chua, 2013; Obeidat et al., 2014; Ranjbarfard et al., 2014; Al Saifi, 2015; Chang \& Lin, 2015; Sangari et al., 2015; Schenk et al., 2015; Suorsa, 2015; Tongo, 2015; Wahba, 2015; Kianto et al., 2016; Lee et al., 2016; Little \& Deokar, 2016; Känsäkoski, 2017; Matoskova \& Smesna, 2017; Pandey et al., 2018; Raudeliūnienė et al., 2018). Many researchers have studied different knowledge management processes, the most recent of them are classified according to (Table 1): creation, generation; sharing, transfer, distribution, dis-semination, conversion; application, reuse, interpretation; storage, codification, retention; acquisition, capture.

Knowledge creation. As defined by Wee and Chua (2013), knowledge creation refers to the new thoughts developed through people interactions of explicit and tacit knowledge. This process contributes to the improvement of operations, allows the identification of new opportunities and increases innovation within organisations. The factors affecting the implementation of this process include employees' competencies and intellectual capabilities in addition to organisational systems and structures. Ranjbarfard et al. (2014) defined knowledge creation as knowledge generation and finding new knowledge through $\mathrm{R} \& \mathrm{D}$, experimentation, lessons learned, innovation and development. Knowledge creation involves the creation of new substance or the substitution of existing substance inside the organisation through social and groups' inter-action and individuals' subjective thoughts (Chang \& Lin, 2015; Tongo, 2015; Lee et al., 2016). Al Saifi (2015) defined knowledge creation as an organizational and societal activity of developing new knowledge. It consists of three steps: encoding and simplifying the available knowledge, capturing and combining current and historical information and producing new knowledge that provides new insight in the organisation. Sangari et al. (2015) realized that organisations should seek and characterize relevant knowledge and find its sources inside and outside the organisations. Knowledge creation involves the capacity to generate knowledge and implement it in the goods and services as well as the systems and procedures of the organisation. According to Schenk et al. (2015), knowledge creation can be improved through a supportive environment for people to generate knowledge and guarantee that the knowledge created serves as part of the organisation system. This might be achieved through encouraging informal communication between individuals inside and outside the firm, integrating the knowledge obtained by these interactions into proper systems and building up formal connections with stakeholders. Fruitful knowledge creation interaction is described as a basic and important practice where past situations and experiences constitute a base for the creation of new knowledge. Wahba (2015) realized that knowledge creation requires the ability to produce new functions from existing knowledge and to develop new skills and expertise. Knowledge creation depends on how much the organisation creates or generates knowledge sources within its borders. The formation of knowledge sources does not happen in deliberation from the present information and capacity of the organisation. Suorsa (2015) defined knowledge creation as the competition and instability in the organisational environment. Kianto et al. (2016) described knowledge creation as the organisation's capacity to generate new and valuable thoughts and resolution concerning many activities within the organization such as goods, services and processes. Knowledge creation is a main factor in improving performance in the unstable environment and supporting innovation and development processes. As analyzed by Little and Deokar (2016), knowledge creation is affected by the capacity of the organisations to engage its employees in social network opportunities. By improving the dedication and motivation of the employees, organisations can benefit from better knowledge creation abilities and alliance with strategic objectives. Känsäkoski (2017) related knowledge creation to innovation which is characterized by the new strategies, procedures structures, processes and methods of cooperation between the concerned individuals. Knowledge creation is also 
defined as the ability to learn from previous experiences and change the future results.

Knowledge acquisition. According to Obeidat et al. (2014), knowledge acquisition involves obtaining new knowledge and information from inside and outside the organisation. Knowledge can be acquired using different means through inherited knowledge from the founders, experimental knowledge from experience and explicit knowledge from people and businesses. Sangari et al. (2015) believed that knowledge acquisition is the process of capturing new substances and substituting available substances inside the organisations. Knowledge must be exchanged with the associates so that knowledge improvement can occur frequently through benchmarking and response from the experience to enhance consequent activities. Kianto et al. (2016) described knowledge acquisition as organisational activities that gather information from different sources. Connections and individual's interactions are basic sources of knowledge for a wide range of organisations. Clients are considered as an essential source of knowledge that will contribute to the organisations' success through their feedback. Also, intellectual intelligence and cooperation with stakeholders represent sources for knowledge acquisition. Pandey et al. (2018) defined knowledge acquisition process as the aggregation of knowledge that exists inside and outside the organisation. Enhanced utilization of the available knowledge depends on its capture and acquisition. The acquisition process accumulates knowledge resulting from experimentation and by determining knowledge gaps through using the best practices that lead to the improvement of the organisation. Knowledge acquisition process depends on the capacity of the organisation to identify, realize and capture knowledge from different resources.

Knowledge organization. Sangari et al. (2015) suggested that new knowledge should to be cultured and organized through recognizing its valuable measurements for various goods and services. Knowledge organisation is the process toward refining, posting and displaying the knowledge.

Knowledge storage. Ranjbarfard et al. (2014) believed that knowledge storage involves storing available, acquired and generated knowledge in repositories. It is about retaining information, documents and experience needed by the management of the organisation. Chang and Lin (2015) indicated that knowledge storage consists of information and knowledge existing in different types collected by people and systems. Organisations should organize and arrange knowledge in order to facilitate its access and dissemination in the organisation. Incorporating knowledge leads to reducing redundancy and duplication which can improve the efficiency of the organisation's activities. Sangari et al. (2015) suggested that knowledge must be stored and arranged in an appropriate form by using repositories, databases and technologies that facilitate the access to it. Organisations should have the capability to store their knowledge in a proper manner and ensure security advancements to restrict the unauthorized access of this knowledge. Tongo (2015) defined knowledge storage as the gathering of knowledge existing in different forms, such as organized information available in repositories and recorded experiences, affected by the quality and the amount of knowledge exchanged and retained by individuals. According to Kianto et al. (2016), knowledge storage and codification represent the processes required to transform tacit knowledge into explicit knowledge, to accumulate documented knowledge and supply this knowledge when needed. It depends on the accessibility of adequate networks and information technology devices, systems and processes, along with the people's skills and experiences, to benefit from the knowledge and store it for future use. Knowledge retention involves managing employees' turnover and the loss of expertise which is considered as a main knowledge source. When employees leave an organisation, their expertise will be lost which makes it necessary of the organisations to retain their best employees in order to retain their knowledge (Kianto et al., 2016).

Knowledge protection. According to Pandey et al. (2018), knowledge protection process is security based and is intended to guard the knowledge inside a firm from illegal and improper utilization and stealing. For an organisation to protect its competitive advantage, it is important to protect its knowledge; else knowledge may lose its value and competitiveness. The usage of technology and proper policies and procedures is required in order to protect knowledge. Tongo (2015) indicated that it will be inefficient and inadequate if individuals don't protect this knowledge from being dispossessed by competitors; else the organisation will lose the competitive advantage.

Knowledge sharing. Wee and Chua (2013) defined knowledge sharing as exchanging knowledge between people to permit the application and redesign of knowledge to benefit from it. 
By this process, individuals can exchange expertise and skills and argue about know-what and know-how processes that contribute to the competitiveness of the organisations but the success of this process depends the most on the interests, morals and motivation of the employees. Obeidat et al. (2014) believed that the capacity to share and disseminate knowledge is crucial for the utilization of intangible assets which are critical to the organisations. Knowledge distribution involves sharing the acquired knowledge between individuals within the organisation. The knowledge sharing process is affected by different factors such as the organisation culture, the employees' morals and behaviors and the technology available to process knowledge sharing. Accordingly, the lack of trust between people is considered as a main barrier to the knowledge sharing process (Obeidat et al., 2014). Ranjbarfard et al. (2014) indicated that knowledge sharing consists of knowledge distribution and dissemination of the knowledge available within the organisations and transferring the best practices. Al Saifi (2015) suggested that knowledge sharing is about making knowledge accessible to other individuals in the organisation. Knowledge sharing is exchanging knowledge, experiences and skills with others which mean donating and receiving knowledge. It is defined as a culture of social interaction. Chang and Lin (2015) indicated that knowledge sharing is an essential procedure of knowledge management in the organisations and involves the transfer of knowledge to areas where it is required and can be utilized. Organisations should deliberately convert tacit knowledge to explicit knowledge in order not to lose it. Lee et al. (2016) described knowledge sharing as an important process for enhancing organisational capacities, which include innovation, development, problem solving, efficiency and profitability. Knowledge sharing happens at the individual and the organisational level. It is defined as employees exchanging their knowledge, experiences and skills inside the organisations. Sangari et al. (2015) defined knowledge sharing and dissemination as the process of exchanging knowledge all through the organisation and involves managing the knowledge transferred in the organisation to improve innovation, raise awareness about past experiences and implement better procedures for the decision making in the future. Tongo (2015) indicated that knowledge sharing influences the adequacy of other knowledge management processes. According to Wahba (2015), knowledge sharing depends on how much the organisation shares knowledge within its borders. The capacity to share and disseminate knowledge empowers the organisation to modify its processes. Knowledge sharing among the members participating in the processes permits better coordination and comprehension of the whole process instead of having divided parts of the process. Känsäkoski (2017) believed that knowledge sharing requires interaction between individuals. The factors affecting knowledge sharing in the organisations consist of the social network structure, location and time occasions, the culture of the organisation, the trust between the members and the employees' motivation. Matoskova and Smesna (2017) defined knowledge sharing as a process in which people share significant information, thoughts, expertise and skills. Knowledge sharing is about making the knowledge available to other individuals in the organisation by transforming it into a clearer, more understandable and beneficial form. Knowledge sharing may happen in a direct way through direct contact between individuals in face to face meeting or phone conversations for example and also it could be indirect through databases and repositories available within the organisation. Knowledge sharing is affected by many factors such as individuals whether managers or employees, organisational culture and the used knowledge sharing tools. Pandey et al. (2018) suggested that knowledge conversion process transforms the acquired knowledge to be useful. The knowledge conversion results an output that is considered as input for knowledge application.

Knowledge application and reuse. Liu et al. (2013) proposed that knowledge reuse consists of engineering know-how, engineering solution and innovations. Knowledge reuse is needed to solve problems in a quick way and to contribute to the performance improvement in the organisations. Wee and Chua (2013) indicated that knowledge reuse involves knowledge application after collection and repackaging. The main objective is to benefit from previous experiences, projects and practices, in order to decrease the duplication of work and reduce errors. Obeidat et al. (2014) believed that after knowledge is collected, its interpretation is required in order for people to understand it. Knowledge interpretation is making use of the information acquired and shared. It requires the use of human and electronic means of communication. Ranjbarfard et al. (2014) described knowledge application as the utilization of knowledge to help in the decision making process, problem solving and automating business activities and giving job training. Chang and Lin (2015) 
suggested that knowledge application is the utilization of knowledge in order to implement strategic decisions, resolve problems, enhance productivity, increase efficiency and decrease costs. Al Saifi (2015) defined knowledge application as the business process through which the organisation has simple access to knowledge which implementation and utilisation will add value to the organisation. Knowledge application includes utilizing knowledge to help in the decision making, the problem solving, and the productivity improvement. Sangari et al. (2015) believed that the main point in knowledge management is to ensure that the acquired knowledge is profitably implemented to benefit the organisation. Knowledge application refers to the usage the knowledge in decision making and problem solving processes. According to Tongo (2015), knowledge application is the utilization of knowledge that was created or stored. Wahba (2015) indicated that knowledge utilization depends on how much the organisation applies the knowledge acquired and shared within its borders. It enables the organisation to benefit from its knowledge resources. Knowledge creation and sharing would not be relevant if the organisation could not utilize this knowledge in an efficient way. The ability to use a related knowledge base in decision making and problem solving enables the organisation to face the business changes which positively affects organisation's structure. As per Känsäkoski (2017), knowledge use is interrelated with knowledge creation and it affects the decision making process. Pandey et al. (2018) defined knowledge application process as the utilization of the knowledge after conversion and it constitutes a crucial part of the overall knowledge management processes because it makes use of the knowledge acquired and converted.

Summarizing the knowledge management processes, studied by Liu et al. 2013; Wee and Chua, 2013; Obeidat et al., 2014; Ranjbarfard et al., 2014; Al Saifi, 2015; Chang and Lin, 2015; Sangari et al., 2015; Schenk et al., 2015; Suorsa, 2015; Tongo, 2015; Wahba, 2015; Kianto et al., 2016; Lee et al., 2016; Little and Deokar, 2016; Känsäkoski, 2017; Matoskova and Smesna, 2017; Pandey et al., 2018; Raudeliūnienè et al., 2018 it was found that most scientists are investigating such main knowledge management processes, as (Figure 1): (1) creation, generation (27\%); (2) sharing, transfer, distribution, dissemination, conversion (25\%); (3) application, reuse, interpretation (24\%); (4) storage, codification, retention (14\%); (5) acquisition, capture (10\%).

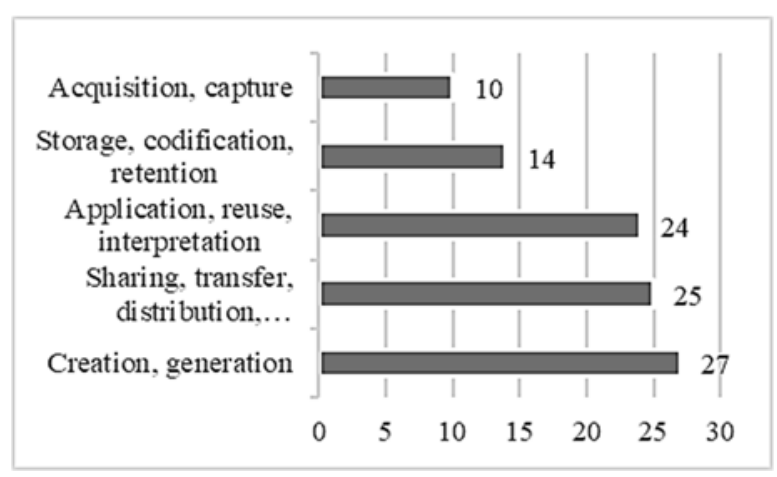

Figure 1. Distribution of knowledge management processes (\%) (source: created by the authors)

These processes are considered as the most important processes that can lead to the desired benefits from knowledge management in organizations' performance. Accordingly, they set the ground for more detailed studies that might include the formation of many hypotheses and the conduct of researches within specific organisations in dif-ferent environments in order to support these hypotheses and demonstrate the importance of these processes and their effects on the organisations' performance.

\section{Conclusions}

In the current dynamic and fast changing environment, knowledge management is acknowledged as the most important factor that helps the organisations to improve their performance and create uniqueness.

Knowledge management is defined as targeted and systematic management of processes, methods and tools, making full use of the organisation's knowledge potential for strategic goals, making effective decisions, implementing and creating its value.

The improvement of organisations' performance depends on their capacity to benefit from the knowledge management processes that best fit their strategies and can add value to their products or services. It is agreed by the scientists and practitioners that successful organisations are those that implemented knowledge management processes and were able to create, protect, share and apply knowledge that affects the delivery of their products or services in an efficient way.

Further research areas could be linked to the assessment of the relationship between knowledge management processes variables and their impact on the organization's performance. 


\section{References}

Acar, M. F., Tarim, M., Zaim, H., Zaim, S., \& Delen, D. (2017). Knowledge management and ERP: complementary or contradictory?. International Journal of Information Management, 37, 703-712.

https://doi.org/10.1016/j.ijinfomgt.2017.05.007

Akbari, N., \& Ghaffari, A. (2017). Verifying relationship of knowledge management initiatives and the empowerment of human resources. Journal of Knowledge Management, 21(5), 1120-1141. https://doi.org/10.1108/JKM-10-2016-0435

Alavijeh, M. R. K., Esmaeili, A., Sepahvand, A., \& Davidavičienè, V. (2018). The effect of customer equity drivers on word-of-mouth behavior with mediating role of customer loyalty and purchase intention. Engineering Economics, 29(2), 236-246.

Al Saifi, S. A. (2015). Positioning organisational culture in knowledge management research. Journal of Knowledge Management, 19(2), 164-189. https://doi.org/10.1108/JKM-07-2014-0287

Anand, A., Kant, R., Patel, D. P., \& Singh, M. D. (2015). Knowledge management implementation: a predictive model using an analytical hierarchical process. Journal of the Knowledge Economy, 6(1), 48-71. https://doi.org/10.1007/s13132-012-0110-y

Ashok, M., Narula, R., \& Martinez-Noya, A. (2016). How do collaboration and investments in knowledge management affect process innovation in services?. Journal of Knowledge Management, 20(5), 1004-1024. https://doi.org/10.1108/JKM-11-2015-0429

Bican, P. M., Guderian, C. C., \& Ringbeck A. (2017). Managing knowledge in open innovation processes: an intellectual property perspective. Journal of Knowledge Management, 21(6), 1384-1405. https://doi.org/10.1108/JKM-11-2016-0509

Cepeda-Carrion, I., Martelo-landroguez, S., Leal-Rodríguez, A. L., \& Leal-Millán, A. (2017). Critical processes of knowledge management: an approach toward the creation of customer value. European Research on Management and Business Economics, 23(1), 1-7.

https://doi.org/10.1016/j.iedeen.2016.03.001

Chang, C., Hsu, M., \& Yen, C. (2012). Factors affecting knowledge management success: the fit perspective. Journal of Knowledge Management, 16(6), 847-861. http://doi.dx.org/10.1108/13673271211276155

Chang, C. L., \& Lin, T. C. (2015). The role of organisational culture in the knowledge management process. Journal of Knowledge Management, 19(3), 433-455. https://doi.org/10.1108/13673271211276155

Chugh, M., Chugh, N., \& Punia, D. K. (2015). Evaluation and analysis of knowledge management best practices in software process improvement a multicase experience. 2015 Second International Conference on Advances in Computing and Communication Engineering (ICACCE), 661-666. https://doi.org/10.1109/ICACCE.2015.76

Edvardsson, I. R., \& Durst, S. (2013). The benefits of knowledge management in small and medium-sized enterprises. Procedia - Social and Behavioral Sciences, 81, 351-354.

https://doi.org/10.1016/j.sbspro.2013.06.441

García-Fernández, M. (2015). How to measure knowledge management: dimensions and model. Vine, 45(1), 107125.

https://doi.org/10.1108/VINE-10-2013-0063
Gupta, P. D., \& Bhattacharya, S. (2016). Impact of knowledge management processes for sustainability of small family businesses: evidences from the brassware sector of moradabad (India). Journal of Information \& Knowledge Management, 15(4), 1-42. https://doi.org/10.1142/S0219649216500404

Hashemi, P., Khadivar, A., \& Shamizanjani, M. (2018). Developing a domain ontology for knowledge management technologies. Online Information Review, 42(1), 28-44. https://doi.org/10.1108/OIR-07-2016-0177

Hegazy, F. M., \& Ghorab, K. E. (2015). The effect of knowledge management processes on organisational business processes' and employees' benefits in an academic institution's portal environment. Communications of the IBIMA, 1-32.

https://doi.org/10.5171/2015.928262

Hesamamiri, R., Mahdavi Mazdeh, M., Jafari, M., \& Shahanaghi, K. (2015). Knowledge management reliability assessment: an empirical investigation. Aslib Journal of Information Management, 67(4), 422-441. https://doi.org/10.1108/AJIM-08-2014-0109

Hesamamiri, R., Mahdavi Mazdeh, M., \& Bourouni, A. (2016). Knowledge-based strategy selection: a hybrid model and its implementation. Journal of Information and Knowledge Management Systems, 46(1), 21-44. https://doi.org/10.1108/VJIKMS-03-2015-0020

Hwang, Y. (2016). A study on the multidimensional information management capability of knowledge workers. Aslib Journal of Information Management, 68(2), 138-154. https://doi.org/10.1108/AJIM-06-2015-0093

Känsäkoski, H. (2017). Information and knowledge processes as a knowledge management framework in health care. Journal of Documentation, 73(4), 748-766. https://doi.org/10.1108/JD-11-2016-0138

Kianto, A., Vanhala, M., \& Heilmann, P. (2016). The impact of knowledge management on job satisfaction. Journal of Knowledge Management, 20(4), 621-636. https://doi.org/10.1108/JKM-10-2015-0398

Lee, J. C., Shiue, Y. C., \& Chen, C. Y. (2016). Examining the impacts of organisational culture and top management support of knowledge sharing on the success of software process improvement. Computers in Human Behavior, 54, 462-474. https://doi.org/10.1016/j.chb.2015.08.030

Little, T. A., \& Deokar, A. V. (2016). Understanding knowledge creation in the context of knowledgeintensive business processes. Journal of Knowledge Management, 20(5), 858-879. https://doi.org/10.1108/JKM-11-2015-0443

Liu, H., Chai, K. H., \& Nebus, F. J. (2013). Balancing codification and personalization for knowledge reuse: a Markov decision process approach. Journal of Knowledge Management, 17(5), 755-772. https://doi.org/10.1108/JKM-04-2013-0127

Luhn, A., Aslanyan, S., Leopoldseder, C., \& Priess, P. (2017). An evaluation of knowledge management system's components and its financial and nonfinancial implications. Entrepreneurship and Sustainability Issues, 5(2), 315-329. https://doi.org/10.9770/jesi.2017.5.2(11)

Mageswari, S. D. U., Sivasubramanian, C., \& Dath, T. N. S. (2017). A comprehensive analysis of knowledge management in Indian manufacturing organisations. Journal of Manufacturing Technology Management, 28(4), 506-530. http://doi.dx.org/10.1108/JMTM-08-2016-0107 
Massingham, P., \& Al Holaibi, M. (2017). Embedding knowledge management into business processes. Knowledge and Process Management, 24(1), 53-71. https://doi.org/10.1002/kpm.1534

Matoskova, J., \& Smesna, P. (2017). Human resource management practices stimulating knowledge sharing. Management \& Marketing Challenges for the Knowledge Society, 12(4), 614-632. https://doi.org/10.1515/mmcks-2017-0036

McIver, D., \& Lepisto, D. A. (2017). Effects of knowledge management on unit performance: examining the moderating role of tacitness and learnability. Journal of Knowledge Management, 21(4), 796-816. https://doi.org/10.1108/JKM-08-2016-0347

Mishra, D., Aydin, S., Mishra, A., \& Ostrovska, S. (2018). Knowledge management in requirement elicitation: situational methods view. Computer Standards and Interfaces, 56, 49-61. https://doi.org/10.1016/j.csi.2017.09.004

Muthuveloo, R., Shanmugam, N., \& Teoh, A. P. (2017). The impact of tacit knowledge management on organisational performance: evidence from Malaysia. Asia Pacific Management Review, 22(4), 192-201. https://doi.org/10.1016/j.apmrv.2017.07.010

Nowacki, R., \& Bachnik, K. (2016). Innovations within knowledge management. Journal of Business Research, 69(5), 1577-1581. https://doi.org/10.1016/j.jbusres.2015.10.020

Obeidat, B. Y., Masa'deh, R. M., \& Abdallah, A. B. (2014). The relationships among human resource management practices, organisational commitment, and knowledge management processes: a structural equation modeling approach. International Journal of Business and Management, 9(3), 9-26. https://doi.org/10.5539/ijbm.v9n3p9

Oluikpe, P. I. (2015). Knowledge creation and utilization in project teams. Journal of Knowledge Management, 19(2), 351-371. https://doi.org/10.1108/JKM-06-2014-0214

Omotayo, F. O. (2015). Knowledge management as an important tool in organisational management: a review of literature. Library Philosophy and Practice, 1-23.

Pandey, S. C., Dutta, A., \& Nayak, A. K. (2018). Organisational capabilities and knowledge management success: a quartet of case studies. Kybernetes, 47(1), 222-238. https://doi.org/10.1108/K-01-2017-0041

Pauleen, D. J., \& Wang, W. Y. C. (2017). Does big data mean big knowledge? KM perspectives on big data and analytics. Journal of Knowledge Management 21(1), 1-6. https://doi.org/10.1108/JKM-08-2016-0339

Pawlowski, J., \& Bick, M. (2012). The global knowledge management framework: towards a theory for knowledge management in globally distributed settings. Electronic Journal of Knowledge Management, 10(1), 92-108.

Pfister, R. A., \& Eppler, M. J. (2012). The benefits of sketching for knowledge management. Journal of Knowledge Management, 16(2), 372-382.

https://doi.org/10.1108/13673271211218924

Ranjbarfard, M., Aghdasi, M., López-Sáez, P., \& Emilio Navas López, J. (2014). The barriers of knowledge generation, storage, distribution and application that impede learning in gas and petroleum organisations. Journal of Knowledge Management, 18(3), 494-522. https://doi.org/10.1108/JKM-08-2013-0324
Raudeliūnienè, J., \& Meidutè-Kavaliauskienė, I. (2016). Editorial: special issue on knowledge management: theory and practice in SMEs. International Journal of Learning and Change, 8(3/4), 193-197.

Raudeliūnienè, J., Davidavičienè, V., \& Jakubavičius, A. (2018). Knowledge management process model. Entrepreneurship and Sustainability Issues, 5(3), 542-554. https://doi.org/10.9770/jesi.2018.5.3(10)

Sangari, M. S., Hosnavi, R., \& Zahedi, M. R. (2015). The impact of knowledge management processes on supply chain performance. The International Journal of Logistics Management, 26(3), 603-626. https://doi.org/10.1108/IJLM-09-2012-0100

Schenk, J., Parent, M. M., MacDonald, D., \& Proulx Therrien, L. (2015). The evolution of knowledge management and transfer processes from domestic to international multi-sport events. European Sport Management Quarterly, 15(5), 535-554. https://doi.org/10.1080/16184742.2015.1091022

Schiuma, G., Carlucci, D., \& Lerro, A. (2012). Managing knowledge processes for value creation. Journal of Information and Knowledge Management Systems, 42(1), 4-14. https://doi.org/10.1108/03055721211207815

Shahzad, K., Bajwa, S. U., Siddiqi, A. F. I., Ahmid, F., \& Raza Sultani, A. (2016). Integrating knowledge management (KM) strategies and processes to enhance organisational creativity and performance. Journal of Modelling in Management, 11(1), 154-179. https://doi.org/10.1108/JM2-07-2014-0061

Suorsa, A. R. (2015). Knowledge creation and play - a phenomenological approach. Journal of Documentation, 71(3), 503-525. https://doi.org/10.1108/JD-11-2013-0152

Tongo, C. I. (2015). Collective work motivation in knowledge based organisations. Team Performance Management: An International Journal, 21(7/8), 386-404. http://doi.dx.org/10.1108/TPM-06-2015-0030

Tubigi, M., \& Alshawi, S. (2015). The impact of knowledge management processes on organisational performance. Journal of Enterprise Information Management, 28(2), 167-185. https://doi.org/10.1108/TPM-06-2015-0030

Valmohammadi, C., \& Ghassemi, A. (2016). Identification and prioritization of the barriers of knowledge management implementation using fuzzy analytical network process. Journal of Information and Knowledge Management Systems, 46(3): 319-337. https://doi.org/10.1108/VJIKMS-08-2015-0046

Wahba, M. (2015). The impact of organisational structure on knowledge management processes in Egyptian context. The Journal of Developing Areas, 49(3), 275-292. https://doi.org/10.1353/jda.2015.0173

Wee, J. C. N., \& Chua, A. Y. K. (2013). The peculiarities of knowledge management processes in SMEs: the case of Singapore. Journal of Knowledge Management, 17(6), 958-972. https://doi.org/10.1108/JKM-04-2013-0163

Yap, J. B. H., \& Lock, A. (2017). Analysing the benefits, techniques, tools and challenges of knowledge management practices in the Malaysian construction SMEs. Journal of Engineering, Design and Technology, 15(6), 803-825. https://doi.org/10.1108/JEDT-07-2017-0067 